\title{
Structure Comparison of Two Coexistent Weevil Rostra on Ailanthus: The Response to Ecological Demands of Egg Deposition
}

\section{Ganyu Zhang}

Beijing Forestry University https://orcid.org/0000-0002-2240-9769

Wenjuan Guo

Beijing Forestry University

Xiaoyi Wang

Beijing Forestry University

Qian Wang

Beijing Forestry University

Jin Cui

Beijing Forestry University

Junbao Wen ( $\square$ wenjb@bjfu.edu.cn )

Beijing Forestry University

\section{Research article}

Keywords: Eucryptorrhynchus scrobiculatus, Eucryptorrhynchus brandti, Ailanthus altissima, rosita, structure, oviposition

Posted Date: September 30th, 2020

DOI: https://doi.org/10.21203/rs.3.rs-74270/v1

License: (c) (i) This work is licensed under a Creative Commons Attribution 4.0 International License. Read Full License 


\section{Abstract}

Background: Elongated rostra play an important role in the egg-laying of weevils, and its emergence is a key event in the adaptive radiation of weevils. Eucryptorrhynchus scrobiculatus Motschulsky and $E$. brandti Harold co-occur on the same only host Ailanthus altissima, while their oviposition sites are different. In order to understand the adaptation between the rostra of the two weevils and their oviposition sites, the structural differentiation of rostra in E. scrobiculatus and E. brandti was compared.

Results: The present study reveals that: (1) The rostra length of E. scrobiculatus and E. brandti was found to be correlated with body size, larger specimens have a proportionally longer rostrum. The increased rostra length is probably a by-product of the larger body sizes. (2) There were significant differences in the external shape of the two rostra, especially the shape of the mandibles of the mouthparts at the apex of the rostra used to excavate an oviposition cavity. (3) There was no difference in the size of the abductor muscles that control the extension of the mandibles, but there were significant differences in the size of the adductor muscles that control the contraction of the mandibles.

Conclusion: These structural differences reflect the functional potential ovipositional tactics of rostra, which is considered to be a response to the ecological demands of egg deposition, and also provide new insights into the coexistence of two weevil species in the same host $A$. altissima.

\section{Background}

Weevils are a type of beetles belonging to the superfamily Curculionidea. They are one of the most diverse family-level groups of extant organisms, with approximately 60,000 described species[1]. The apical evolution of weevil is a key innovation that enables the group to feed and lay eggs in almost all plant tissues, resulting in different life histories and great diversity. They exhibit a vastly extended rostrum from the forehead, particularly in the females[2-4]. The tip or apex of the rostrum is called mouthpart, it is used to excavate an oviposition cavity by chewing a narrow opening into the tissues of the host. The use of the rostrum in oviposition site preparation is considered the key adaptation that facilitates circumventing of the physical defenses of the plant (shells, spines), avoidance of desiccation of the larvae, and initiation and maintenance of attachment to the host[1].

The variation of rostra type is considered to be the product of ecological action, and the rostrum size of each species is critical to their lifestyle and survival patterns. For example, the species of the genus Curculio attack a wide range of host plants is hypothesized to be caused by the ecological morphological adaptation of the oviposition site, and the size of the host seed is the reason for a morphological change in the size of rostrum[2]. Among the different populations of the Curculio camelliae, the rostrum length of the female is related to the thickness of the Camellia seed coat $[4,5]$. The indispensable tool for ecologists and evolutionary biologists to elucidate patterns and explanations is morphological analysis, a method that can attempt to link the structure and function of organisms with the characteristics of related environments[6]. For structure-function relationships, morphological studies can reveal selectivity factors 
in the environment and the limitations of phenotype responses to these factors. Mouthparts and Mandibulas of the adult females of Doubledaya bucculenta Lewis (Coleoptera: Erotylidae: Languriinae) exhibit distinct directional asymmetry compared to males. This structure helps with oviposition in the internodes that higher fitness to the offspring[7]. Gertha wilhelm showed that the rostrum of females and males of Rhopalapion longirostre (Coleoptera, Weevilidae) has dimorphism. Rhopalapion longirostre bores egg channels into the buds and the female rostrum is twice as long and its surface is smoother than in the male[8]. Bland compared the mouthparts and sensors of Hypera postica and Hypera brunneipennis, which found that the types and numbers of cone sensors were the same at the endpoint, but the shape and size of the mandible were different $[9,10]$.

Ailanthus altissima (Mill). Swingle. A. altissima, also called the tree of heaven, is a common afforestation tree and street tree in China but is an invasive species that is not conducive to the growth of native plants in the United States[11, 12]. It is a species native to China and North Vietnam[13, 14]. However, the tree species have been severely damaged due to two major pests, Eucryptorrhynchus scrobiculatus Motschulsky and E. brandti Harold, causing severe economic losses in recent years. According to statistics, affected by two kinds of weevils, the damage rate of Ailanthus altissima in Huaibei area of China was $80 \%$, the damage rate of Ailanthus altissima in Ningxia area was more than $15 \%$. The more serious was that the damage rate of Ailanthus altissima in Aksu City, Xinjiang was as high as 99.4\%[1518]. When the damage was serious, the number of E.scrobiculatus and E.brandti on a tree can be up to more than 360. The larvae feeding on the cutting tissue of the plant caused the death of Ailanthus altissima, which posed a serious threat to the greening forests and farmland protection forest nets around the villages and towns dominated by Ailanthus. Based on the above circumstances, the State Forestry Administration of China successively included the E.scrobiculatus and the E.brandti in the "National Forestry Hazardous and Pest List" in 2003 and 2013[19].

Eucryptorrhynchus scrobiculatus Motschulsky and E. brandti Harold belong to Coleoptera, Curculionidae, Cryptorrhychinae, Eucryptorrhynchus[20,21]. These two species only harm Ailanthus altissima and its variant $A$. altissima var. Qiantouchun and often appear together on the host. The genetic distance of these two curculionid species was 0.173 , and their differentiation time was about 3.76 million years ago[22]. Speciation is driven primarily by natural selection when ecological opportunities abound, divergent natural selection causes differentiation in phenotypic traits influencing the use of the environment, and speciation ultimately may follow. Alternatively, speciation is driven by mechanisms having little to do with differences between environments or ecological opportunity (e.g., genetic drift, hybridization, chromosome rearrangement). Phenotype divergence may occur independently of this process or it may occur later, possibly in response to interspecific competition or other interactions $[2,23]$. In a previous study, we have known these two weevils coexist on a single host, there were significant differences in the oviposition sites. E. scrobiculatus females laid eggs in the soil near A. altissima and leaf petioles, while $E$. brandti females laid eggs in the trunk of $A$. altissima[24]. Besides, through behavioral observations, we found that they must first excavate an oviposition cavity before they lay eggs, and excavating must use their rostra[24, 25]. Before this, we have made the following speculation by studying the oviposition sites and oviposition preference of two species of weevils: The difference in 
sites for egg-laying between E.scrobiculatus and E.brandti may be caused by the adaptation of their rostra to the ecological properties of the oviposition sites, and the morphology of their rostra may be related to the hardness of the oviposition substrate surface[24]. Therefore, in this study, we hypothesize that these two species of weevils formed different rostrum-type structural during evolution to adapt to behavioral and ecological needs (i.e. laying eggs in different sites). Furthermore, we assume that the internal and external rostrum morphology reflects those different demands. By a detailed comparison of the inner and outer head morphology of the two species, we seek to show the relationships between specific oviposition sites and morphological traits of the investigated weevils and explain why the two weevils can coexist on the same host A.altissima.

\section{Results}

External morphology of rostra

As in all weevils, the rostrum of E. scrobiculatus and E. brandti is an elongation of the frontal part of the head (Fig. 1). It projects forward, is slightly arched, and houses the mouthparts at the apex. Both the rostrum and main head capsule are well sclerotized. From the overall appearance, the external structure of the rostrum of E. scrobiculatus E. brandti was similar, but the latter was significantly smaller than the former (RL1:4.46 $\pm 0.03 \mathrm{~mm}$ vs. $3.14 \pm 0.03 \mathrm{~mm}, \mathrm{~F}=2.735, P<0.001, \mathrm{RL} 2: 6.42 \pm 0.03 \mathrm{~mm}$ vs. $4.58 \pm$ $0.03 \mathrm{~mm}, \mathrm{~F}=0.18, P<0.001)$. Here, in order to ensure the accuracy of the data, we used two indexes to represent the rostrum length (R1: Length of rostrum but excluding head capsule; R2: length of the rostrum including head capsule), because there may be errors caused by artificial removal of the head capsule during the experimental operation.

The allometric relationship between body size and rostrum length

\section{Different sexes of the same weevil: Male and female of $E$. scrobiculatus}

The test for the allometric relationship between E. scrobiculatus (Female \& Male) body size and rostrum length revealed that (Fig. $2, A)$ slope $(b=0.820)$ of common function for both species was larger than the slope $(b=0.752)$ of $E$. scrobiculatus females, while smaller than the slope $(b=0.913)$ of $E$. scrobiculatus males (95\% Cl: $0.72-0.92 ; t=16.43 ; P<0.001)$. The difference between the slopes of $E$. scrobiculatus females and $E$. scrobiculatus males were not significant $\left(F_{1,92}=2.581, P=0.1116>0.05\right)$. The ANCOVA (analysis of covariance) confirmed the strong positive effect of body size on rostrum length $(F=270.061$, $P<0.001$ ). Conversely, neither the factor sex nor its interaction with body size significant (respectively, $\mathrm{F}=$ 1.189; $P=0.278$ and $\mathrm{F}=2.581, P=0.112$ ), indicating that rostrum length was determined by body size irrespective of sex, and that allometric relationship of body size/rostrum length did not differ between different sexes of E.scrobiculatus. 


\section{Different sexes of the same weevil: Male and female of $E$. brandti}

The test for the allometric relationship between E. brandti (Female \& Male) body size and rostrum length revealed that (Fig. 2, B) slope $(b=0.7922)$ of the pooled was larger than the slope $(b=0.7476)$ of $E$. brandti females, while smaller than the slope $(b=0.8227)$ of $E$. brandti males $(95 \% \mathrm{Cl}: 0.67-0.92, t=$ $12.689 ; P<0.001)$. The difference between the slopes of $E$. brandti females and $E$. brandti males were not significant $\left(F_{1,96}=0.346, P=0.5578>0.05\right)$. The ANCOVA confirmed the strong positive effect of body size on rostrum length $(F=161.012, P<0.001)$. Conversely, neither the factor sex nor its interaction with body size significant (respectively, $\mathrm{F}=0.538, P=0.465$ and $\mathrm{F}=0.346, P=0.558$ ), indicating that rostrum length was determined by body size irrespective of sex, and that allometric relationship of body size/rostrum length did not differ between $E$. brandti females and E. brandti males.

\section{Different species of the same sex: females of $E$. scrobiculatus and E. brandti}

The test for the allometric relationship between $E$. scrobiculatus females and $E$. brandti females body size and rostrum length revealed that (Fig. $2, C)$ slope $(b=0.7504)$ of common function for both species was larger than the slope $(b=0.7476)$ of $E$. brandti females, while smaller than the slope $(b=0.7523)$ of $E$. scrobiculatus females $(95 \% \mathrm{Cl}: 0.63-0.87, \mathrm{t}=12.538 ; P<0.001)$. The difference between the slopes of $E$. scrobiculatus females and $E$. brandti females were not significant $\left(F_{1,100}=0.0001417, P=0.9700>0.05\right)$. The ANCOVA confirmed the strong positive effect of body size on rostrum length $(F=157.197, P<0.001)$. Conversely, neither the factor species nor its interaction with body size significant (respectively, $F=1.026$, $P=0.314$ and $\mathrm{F}=0.001, P=0.970$ ), indicating that rostrum length was determined by body size irrespective of species, and that allometric relationship of body size/rostrum length did not differ between E.scrobiculatus females and E. brandti females.

\section{Different species of the same sex: males of $E$. scrobiculatus and E. brandti}

The test for the allometric relationship between E. scrobiculatus males and E.bandti males body size and rostrum length revealed that (Fig. $2, D)$ slope $(b=0.8608)$ of common function for both species was larger than the slope $(b=0.8227)$ of E.bandti males, while smaller than the slope $(b=0.9133)$ of $E$. scrobiculatus males (95\% Cl:0.76-0.96; $\mathrm{t}=16.538 ; P<0.001)$. The difference between the slopes of $E$. scrobiculatus males and $E$. brandti males were not significant $\left(F_{1,88}=0.7367, P=0.3931>0.05\right)$. The ANCOVA confirmed the strong positive effect of body size on rostrum length $(F=273.489, P<0.001)$. Conversely, neither the factor species nor its interaction with body size significant (respectively, $F=0.206$, $P=0.651$ and $\mathrm{F}=0.737, P=0.393$ ), indicating that rostrum length was determined by body size irrespective of species, and that allometric relationship of body size/rostrum length did not differ between E.scrobiculatus males and E. brandti males. 
The mouthpart structure was the same in both weevils, with components including the labrum, mandibles, maxillae, labium, and hypopharynx, all situated at the tip of a long rostrum, which was formed by elongation of the front and, to a lesser extent, the vertex. Comparing the fine structures of two beetle female rostrums (Fig. 3), we could see the shape of the two species females' rostrums look similar, while the rostrum of E. scrobiculatus female was stout, densely covered with setae and minute pores, the rostrum of $E$. brandti female was thin, and smooth, with much fewer setae and pores. The biggest difference was in the mouthparts. The maxillae and labium of E. scrobiculatus were shorter than the mandibles and encased by the mandibles, while the maxillae and labium of E. brandti were almost as long as the mandibles and not enclosed by mandibles. The mandibles of two weevils were massive and irregularly semi-globular, their inner faces being roughly plane, and their outer ones strongly convex. They beard prominent teeth on their anterior margins, and differences in the form and extent of the teeth result in the mandibles presenting a marked asymmetry. Each mandible of E.scrobiculatus possessed two teeth, a conspicuous large apical tooth and a small tooth, these two teeth differ greatly in size. Each mandible of $E$. brandti also had two teeth, but the difference in size between the two teeth was not very obvious, almost each one occupied half of the top of the mandible.

X-raymicrotomography and 3D Model Reconstruction

Using three-dimensional reconstruction technology, we constructed the two species of weevil's internal structures, as shown in Fig. 4, the references for the definition and naming of each part are as follows[8, $26,27]$. There is no big difference in the basic internal structure of the two weevils.

While, scanning electron microscopy has shown that there are significant differences in the structure of the mandibles of the two weevil females. Therefore, based on the construction of the internal structure of the weevil's rostrum and head capsule, we compared the size of the mandibular muscles volume of $E$. scrobiculatus females and $E$. brandti females. The mandibular muscles, the adductors and abductors, work together to control the movement of the mandibular. The results showed (Fig. 5) that the adductor muscle of E. scrobiculatus females occupying $5.29 \%$ of the head volume was smaller than that of E.brandtifemales occupying $6.16 \%(F=15.838, P=0.016<0.05)$, while there was no significant difference between the two types of weevil adductor volume (ES2.49\% VS EB 2.13\% F = 0.542, $p=0.502>$ 0.05). But overall, no matter whether it was E. scrobiculatus females or $E$. brandti females, the adductor muscle was significantly larger than the abductor muscle (EB: $F=131.853, P<0.05$; $E S: F=45.370, P=$ $0.003<0.05$ ). These volumes allow an accurate relative comparison, although they do not represent absolute volumes in the living animals because fixation and dehydration may significantly cause shrinkage in muscle tissues.

\section{Discussion}

It has reported that the genetic distance between E. scrobiculatus and E. brandti was 0.173 , the differentiation time of the two weevils can be traced back to about 3.76 million years ago. It can be 
speculated that before this time, the two beetles may be the same species. In order to reduce intra-species competition to adapt to changes in certain environments, they form niche differentiation, and groups occupying different niches have barriers to gene communication, and new species are formed through reproductive isolation[22]. In this long-term evolution process, they have formed into different forms to meet different ecological demands. In the previous study we have known, in the long-term evolution process, E. scrobiculatus and E. brandti utilized different oviposition sites to facilitate coexistence on the single host $A$. altissima. Further observation of oviposition behavior revealed that females must dig a oviposition hole with their rostra before laying eggs[24, 25]. Therefore, we further put forward the hypothesis that the difference in the egg-laying positions of the two kinds of weevils may be due to the difference in the structure of their rostrums. In other words, in order to adapt to different oviposition positions, the two weevils formed different rostrum shapes to ensure the development of offspring.

Regarding the elongated rostrum, the main difference in length between the male and female weevils of some species has been well known. This was mentioned in Kirby \& Spence "Introduction to Entomology" [28]. Darwin been sufficiently understood, but it must be seen in relation 'different habits of life and not at all, or only indirectly, to the reproductive functions' mentioned that sexual dimorphism in weevil rostra and many similar examples had not (in the sense of sexual selection) [29]. Exaggerated female rostra are well documented within the Curculionidae[4, 26, 30-32]. For example, there was obvious external sexual dimorphism in the length of their rostra between the male and female rostra of Rhopalapion longirostre (Coleoptera: Curculionoidea), and the female rostrum was twice as long the male. The elongated female snout of $R$. longirostre was a response to the requirements of boring egg channels of maximal depth into the buds of the host plant[8]. In our study, we have known E. brandti female rostra were significantly longer than males, this result seemd to be consistent with Gertha's results on sexual dimorphism of $R$. longirostre[8]. However, the difference was that we found there were also significant differences in female and male body size, and rostrum length was found to be correlated with body size. For $E$. brandti, the body size and rostrum length between males and females were significantly different, both female body size and rostrum length are greater than male (Figure S1, B). While the slope value of allometric did not differ between $E$. brandtifemales and males (Fig. 2, B). Therefore, we suppose that the E. brandtifemale rostrum length was caused by body size. This result also applied to E. scrobiculatus. For E. scrobiculatus, there was no difference in body size and rostrum length between males and females (Figure S1, A), and the slope value of allometric did not differ between E. scrobiculatus females and males (Fig. 2, A). In addition, comparing the two weevil females also proved that the E. scrobiculatus rostrum was longer than the E. brandti, and E. scrobiculatus's body was longer than the E. brandti. This showed that larger specimens had proportionally longer rostrum. The slope of the allometric function relating body size and rostrum length was little than one, showing that rostrum length does not increase isometrically with body size. This result was consistent with the speculation. For large Curculio elephas and the small-bodied Curculio glandium co-occur in oak forests, there were no interspecific differences in adult female body size to rostrum length allometric relationships, and rostrum length was equally correlated with body size in either species[33]. The increased rostrum length was probably a by-product of the larger body sizes of individuals emerging from bigger acorns. There was no divergence in adult allometry between the same 
species of different sex and same sex of different species of E. scrobiculatus and E. brandti (Fig. 2). Therefore, we speculate that the rostrum length of E. scrobiculatus and E. brandti which was caused by body size was not a feature of the two weevil's adaptation to the oviposition site, it was probably a byproduct of the larger body sizes. Perhaps the co-vary in body features and exaggerated feeding traits, rather than just exaggerated rostrum length, is one of the performances of the two kinds of weevil's adaptation to the environment.

In addition, we know that exaggerated female rostrum is an important structure in the oviposition process of weevil. Antliarhinus zamiae females use their extremely long rostra to chew through the cones of their host plants, species of the cycad genus Encephalartos (Zamiaceae) and deposit their eggs into the cycad's ovules[31,34]. That species of the genus Curculio attack a wide range of host plants is hypothesized to be a result of ecomorphological adaptations to oviposition site, and seed size has been postulated to be responsible for morphological changes in rostrum size[2]. A series of studies show in great detail that the length of the female rostrum is closely related to the relative thickness of the pericarp of the host plant Camellia japonica in different populations of the weevil species Curculio camelliae (Curculionidae) [3-5]. It was argued that natural selection drives the coevolutionary arms race between the weevil and its host plant, and the specific morphological changes of the curculio's rostrum are the result of ecological morphological adaptation to the oviposition site. Bland compared the mouthparts and sensors of Hypera postica and Hypera brunneipennis and found that the types and number of tapered sensors at the end of the lower jaw were the same, but the shape and size of the mandibles were different[9].In our study, the gross morphological features of the mouthparts of E. scrobiculatus and $E$. brandti are similar to those reported for other weevils[32, 35-39], but their fine structure is slightly different. The highly sclerotized left and right mandibles, hinged to the later apical margin of the rostrum by well-developed dorsal and ventral articulations, and coming together medially, are massive and irregularly semi-globular. The asymmetrical mandibles look like palm-shaped pliers, the outer surface protrudes in an arc shape. When laying eggs, the left and right mandibles bite each other to excavate holes. Each mandible of E.scrobiculatus female possesses two teeth, a conspicuous large apical tooth and a small tooth, these two teeth differ greatly in size (Fig. 3, E, G). The bigger tooth is round and blunt. This structure can not only reduce the stress concentration but also enhance the mechanical strength of the biological material to adapt to the environmental conditions and improve the wear resistance under the action of soil abrasives. It can also improve the distribution of soil stress at the end, change the shape of the compacted soil, and reduce soil adhesion[40]. Each mandible of $E$. brandti female also has two teeth, but the difference in size between the two teeth is not obvious, almost either one occupies half of the top of the mandible (Fig. 3, F, H). These two teeth rubbing against each other is more conducive to biting the bark, and the slender and smooth rostrum is more conducive to females drilling holes on the hard trunk. Forsythe compared the shapes of mouthparts of some ground beetles (Carabidae), find different mandibular structures adapt to different foods and have different feeding habits[41]. In our study we speculate that the difference in the fine structure of the two rostra of the two weevils is an adaptation to the oviposition sites. The rostrum of E. scrobiculatus is stout, densely covered with setae and minute pores, the mandible of mouthparts possesses two teeth, the two teeth are not the same size. 
Such structural features are more conducive to digging in the soil. While the rostrum of $E$. brandti female is thin, and smooth, with much fewer setae and pores. Two teeth of little different in size rubbing against each other are more conducive to biting the bark, and the slender and smooth rostrum is more conducive to females drilling holes on the hard trunk.

In addition, we also compared the fine structure of the rostrum between males and females of the same species, but found that the external morphological structure did not differ much in sex, except for the difference between the body length and the rostrum length of $E$. brandti, there was no sexual dimorphism between males and females. However, a comparison of the internal male and female mandibular muscles of E. scrobiculatus and E. brandti revealed a distinct sexual dimorphism. It can be seen on the slice of the micro-CT, whether E. scrobiculatus or E. brandti, the female muscles (mandible adductor muscle and mandible abductor muscle) are more developed than the male (Figure S2). Based on image segmentation and three-dimensional reconstruction, we compared the proportion of mandibular muscles between males and females of the same species. The results also show that the female muscle volume (mandible adductor muscle and mandible abductor muscle) was much larger than the male ( $E$. scrobiculatus: $\mathrm{V}_{\mathrm{adF}} 5.42 \%$ vs $\mathrm{V}_{\mathrm{adM}} 3.76 \%, \mathrm{~V}_{\mathrm{abF}} 3.3 \%$ vs $\mathrm{V}_{\mathrm{abM}} 2.05 \%$; E. brandti: $\mathrm{V}_{\mathrm{adF}} 6.56 \%$ vs $\mathrm{V}_{\mathrm{adM}} 4.34 \%$, $\mathrm{V}_{\mathrm{abF}} 2.7 \%$ vs $\mathrm{V}_{\mathrm{abM}} 1.48 \%$. adF = the mandible adductor muscle of female; adM = the mandible adductor muscle of male, $a b F=$ the mandible abductor muscle of female, $a b M=$ the mandible abductor muscle of male). Gertha compared the mandibular muscles of $R$. longirostre male and female, the results also showed a distinct sexual dimorphism[8]. The female mandibular adductor muscle and the mandibular abductor muscle were significantly larger than that of the male. This difference between male and female muscles indicates that females need more muscle to increase muscle strength for excavating oviposition sites. In our study, because the microscopic sections of male and female weevils can see the difference in muscle volume, we only selected a single sample randomly for comparison and did not conduct an analysis of variance.

Further, we compared the volume of the two weevils' female muscles to analyze the response to the oviposition sites. In this experiment, unlike the male and female, it was difficult to see the muscle size of the two females on the micro-CT slice level (Figure S2). Therefore, we conducted an analysis of variance by three-dimensionally reconstructing and calculating the muscles of multiple sample females. The results were shown in the Fig. 5 , the mandibular adductor muscle of $E$. brandti females were significantly larger than that of E. scrobiculatus females, but the mandibular abductor muscle was not different between the two females. Previous studies on the oviposition behavior of the two weevil species have revealed that during the oviposition process, the mandibular of the female was continuously opened and closed to excavate an oval oviposition cavity hole at the oviposition substrate[24, 25], and the mandibular is jointly controlled by the adductor and abductor. The adductor muscle controls the mandibular occlusion, and the abductor muscle controls the mandibular extension[27]. E. scrobiculatus females had no difference in abductor muscles than $E$. brandti females, but the adductor muscles of $E$. scrobiculatus females were smaller than that of $E$. brandti females. From this, we can speculate that there was no 
difference in the amount of external tension between $E$. scrobiculatus females and $E$. brandti, but the bite force on the mandibular of E. brandti females was larger than that of E. scrobiculatus females.

\section{Conclusions}

Different structures determine different functions. In this study, we have compared the internal and external structures morphology of rostrum and head of the two species in detail. The results are consistent with our hypothesis that there are some differences in the rostra of the two weevil species to adapt to different oviposition sites. During the long-term evolution, the two species of weevils show structural differences that reflect the functional potential ovipositional tactics of rostra in the outer and inner morphology to adapt to ecological demands of egg deposition, these results also provide new insights into the coexistence of two weevil species in the same host $A$. altissima. In addition to pest control, the comparison of the two weevil rostra structures provides guidelines for the design of oviposition substrates for the large-scale indoor breeding of the two weevils, as well as provided new inspiration for the prevention and control of these two weevils in the field from the perspective of changing the insect oviposition substrate.

\section{Material And Method}

Study objects

Eucryptorrhynchus scrobiculatus adults and E. brandti adults were collected from an A. altissima forest in Xiaoxingdun village $\left(38^{\circ} 51^{\prime} 27.44^{\prime \prime} \mathrm{N}, 106^{\circ} 31^{\prime} 33.03^{\prime \prime} \mathrm{E}\right)$, Ningxia Hui Autonomous, China, from July 2018 to September 2019.

\section{External morphology data}

The outside micrometer (Guanglu 211-101E, measuring range $0-25 \mathrm{~mm}$, Resolution of $0.001 \mathrm{~mm}$ ) was used to collect the external morphology data of E. scrobiculatus (54 Female $\times 43$ Male) and E. brandti (51 Female $\times 52$ Male). Rostrum length and elytra length of the two species weevils were measured. Rostrum images of E. scrobiculatus and E. brandti females were taken with a Leica M205FA stereomicroscope (Leica Microsystems).

Scanning electron microscopy

Seven females of E. scrobiculatus and $E$. brandti were fixed in $70 \%$ ethanol. The rostrum with mouthparts was first removed from the body with fine forceps and needle. Then the samples were fixed in $2.5 \%$ glutaraldehyde for two hours and washed with phosphate buffer at $\mathrm{pH} 7.8$ three times for $15 \mathrm{~min}$. The samples were then dehydrated in a graded alcohol series of $30 \%, 50 \% \otimes 70 \% \varangle 80 \% \otimes 90 \% \otimes 95 \% \otimes 100 \%$, in each case for $15 \mathrm{~min}$, and with one repeat at $100 \%$ ethanol. The $100 \%$ ethanol was then replaced with $100 \%$ tertbutanol in a graded series (3:1, 2:2, and 1:3, by volume) for 15 min at each step. Specimens were stored in $100 \%$ tertbutanol for $30 \mathrm{~min}$. The specimens were critical point-dried, mounted on stubs with 
double-side sticky tape, and were sputter-coated with gold by an E-1010 sputter ion instrument (Hitachi, Tokyo, Japan) before examination with an S-3400N (Hitachi) scanning electron microscope at an accelerating voltage of $0.5-30 \mathrm{KV}$.

\section{X-raymicrotomography (MICROCT)}

The rostrum with mouthpart was also first removed from the body with fine forceps and needle. Then these samples were dehydrated in alcohol. The steps of gradient dehydration in alcohol were as follows: $50 \%$ alcohol, $70 \%$ alcohol, $75 \%$ alcohol, $80 \%$ alcohol, $85 \%$ alcohol, $90 \%$ alcohol, $100 \%$ alcohol (3 times), each interval 10-15 minutes. Finally, dehydrate with acetone 3 times for 30 minutes each. The prepared samples were scanned using a 3D X-ray microscope (nanoVoxel-3000, Sanying Precision Instrument Co., Ltd.) The specific steps are as follows: the sample was glued to the carbon fiber rod, clamped with a holder, and placed in a test device for 10 minutes. Turn on the power switch of the device and enter the appropriate test conditions: $60.0 \mathrm{kV}, 80.0 \mu \mathrm{mA}, 0.60 \mathrm{~s}$. Turn on dynamic scanning and adjust the rotation center of the sample to ensure that the area measured by the sample was always in the field of view during the test. Select the $\mathrm{CT}$ test to start scanning. After the scan is completed, transfer the data collected by the device to the back-end machine and import the analysis software.

\section{D Model Reconstruction}

The imported data was analyzed with Avizo 9.0.1 to reconstruct the target structure. Morphological structures were segmented manually using mainly the brush, lasso, magic wand tool of the Avizo Segmentation editor. The main structures inside the weevils' head were divided and extracted from the three angles of the test sample $X Y, X Z$, and $Y Z$ axes. Different structures are marked in different colors and combined in the project view of Avizo and were trimmed and smoothed with volume edit. Finally, solid and transparent surfaces were rendered using multiple viewers. The internal space of the entire head (including the head capsule and rostrum) was filled and the antennae were removed using the volume editing tool as the denominator of the volume ratio analysis. Take the segmented muscle volume as the input image, the head fill and remove antennal as input image mask by volume fraction of Avizo to calculate volumes proportion of the muscle.

Statistical analyses

We performed ANOVAs to compare the body size (elytra length) and rostrum length between the adult of E.scrobiculatus and E.brandti. To detect any interspecific difference in the scaling relationship between adult rostrum length and body size, we compared different sexes of the same weevil and different species of the same sex, adapting the methodology used by Toju and Sota [4] for intraspecific population analyses. Allometry was assessed using the function $y=a x^{b}$, where $x$ and $y$ correspond to body and rostrum length, respectively. This was log-transformed to

give $\log y=\log a+b \log x$ and the slope of "b" was calculated to assess the allometric relationship between body size and rostrum length. We then performed an ANCOVA (Analysis of Variance) in which 
log-transformed rostrum length was the dependent variable, the species or sexes was the independent factor, and log-transformed body size was the covariate. We assessed whether the allometric relationship between rostrum length and body size (the slope of the function) differed between species or sexes and whether the species membership/sexes had any independent effect on rostrum length. In addition, we used a one-way ANOVA method to compare the difference in rostra length and muscles volume between the two weevils.

\section{Abbreviations}

ES: E. scrobiculatus

EB: E.brandti

adF $=$ the mandible adductor muscle of female

adM= the mandible adductor muscle of male

$a b F=$ the mandible abductor muscle of female

$a b M=$ the mandible abductor muscle of male

\section{Declarations}

\section{Availability of data and materials}

The datasets during and/or analysed during the current study available from the corresponding author on reasonable request.

\section{Acknowledgments}

Thanks to the Forestry Bureau in Lingwu City for providing the laboratory. We are grateful to Sanying Precision Instruments Co., Ltd for 3D X-ray microscope. We also thanks to the engineer Mr. Wan for his technical support in the use of Avizo software.

\section{Funding}

This research was supported by National Natural Sciences Foundation of China (Grant No. 31770691) and National Key R\&D Program of China (2018YFC1200400)

\section{Author information}

\section{Affiliations}

Beijing Key Laboratory for Forest Pest Control, Beijing Forestry University, Beijing 100083, China 
Ganyu Zhang, Wenjuan Guo, Xiaoyi Wang, Qian Wang, Jin Cui, Junbao Wen

\section{Contributions}

Conceptualization: Ganyu Zhang and Junbao Wen; methodology: Ganyu Zhang, Wenjuan Guo, Xiaoyi Wang and Jin Cui; validation: Ganyu Zhang; formal analysis: Ganyu Zhang; investigation: Ganyu Zhang; draft preparation: Ganyu Zhang; writing-review and editing: Ganyu Zhang and Junbao Wen; visualization: Ganyu Zhang; supervision: Junbao Wen; project administration: Junbao Wen; funding acquisition: Junbao Wen. All authors contributed to the experiments and approved the final manuscript.

\section{Corresponding author}

Correspondence to Junbao Wen

\section{Ethics declarations}

Ethics approval and consent to participate

Not applicable.

Consent for publication

Not applicable.

Competing interests

The authors declare that they have no competing interests.

\section{References}

1. Anderson R. An evolutionary perspective on diversity in Curculionoidea. Memoirs of the Entomological Society of Washington. 1995;14:103-4.

2. Joseph H, Alfried PV. Ecomorphological Adaptation of Acorn Weevils to Their Oviposition Site. Evolution. 2004;58(9):1971-83. http://dx.doi.org/10.1111/j.0014-3820.2004.tb00483.x.

3. Toju H, Sota T. Imbalance of Predator and Prey Armament: Geographic Clines in Phenotypic Interface and Natural Selection. Am Nat. 2006;167(1):105-17. http://dx.doi.org/10.1086/498277.

4. Toju $\mathrm{H}$, Sota $\mathrm{T}$. Adaptive divergence of scaling relationships mediates the arms race between a weevil and its host plant. Biol Let. 2006;2(4):539-42. http://dx.doi.org/10.1098/rsbl.2006.0514.

5. Toju H, Sota T. Do arms races punctuate evolutionary stasis? Unified insights from phylogeny, phylogeography and microevolutionary processes. Mol Ecol. 2009;18(18):3940-54. http://dx.doi.org/10.1111/j.1365-294X.2009.04340.x.

6. Losos JBM, Donald B. Adaptation, Constraint, and the Comparative Method: Phylogenetic Issues and Methods Wainwright and S M Reilly, eds Ecological morphology: integrative organismal biology Univ 
of Chicago Press, Chicago. 1994:60-98.

7. Toki W, Togashi K. Relationship between Oviposition Site Selection and Mandibular Asymmetry in Two Species of Lizard Beetles, Anadastus Pulchelloides Nakane and Doubledaya bucculenta Lewis (Coleoptera: Erotylidae: Languriinae). Coleopterists Bulletin. 2013;67(3):360-7. http://dx.doi.org/10.1649/0010-065X-67.3.360.

8. Wilhelm G, Handschuh S, Plant J, Nemeschkal HL. Sexual dimorphism in head structures of the weevil Rhopalapion longirostre (Olivier 1807) (Coleoptera: Curculionoidea): a response to ecological demands of egg deposition. Biological Journal of The Linnean Society. 2011;104(3):642-60. http://dx.doi.org/10.1111/j.1095-8312.2011.01751.x.

9. Bland RG. Mouthpart Sensilla and Mandibles of the Adult Alfalfa Weevil Hypera postica and the Egyptian Alfalfa Weevil H. brunneipennis (Coleoptera: Curculionidae). Annals of the Entomological Society of America. 1984. http://dx.doi.org/10.1093/aesa/77.6.720.

10. Bland RG. Sensilla on the antennae, mouthparts, and body of the larva of the alfalfa weevil, hypera postica (gyllenhal) (Coleoptera: Curculionidae). International Journal of Insect Morphology Embryology. 1983;12:261-72. http://dx.doi.org/10.1016/0020-7322(83)90022-3.

11. Davies PA. The history, distribution, and value of Allanthus in North America. Transkyacadsci. 1940.

12. Herrick NJ, Mcavoy TJ, Snyder AL, Salom SM, Kok LT. Host-range testing of Eucryptorrhynchus brandti (Coleoptera: Curculionidae), a candidate for biological control of tree-of-heaven, Ailanthus altissima. Environ Entomol. 2012;41(1):118-24. http://dx.doi.org/10.1603/EN11153.

13. Herrick NJ, Salom SM, Kok LT, Mcavoy TJ. Foliage feeding tests of Eucryptorrhynchus brandti (Harold) (Coleoptera: Curculionidae), a potential biological control agent of the tree-of-heaven, Ailanthus altissima. 2009.

14. Kowarik I, Säumel I. Biological flora of Central Europe: Ailanthus altissima (Mill.) Swingle. Perspectives in Plant Ecology Evolution \& Systematics. 2007;8(4):0-237. http://dx.doi.org/10.1016/j.ppees.2007.03.002.

15. Ge T. Bionomics of Eucryptorrhynchus brandti. Forest Pest Disease. 2000;19(2):17-8.

16. Zhou L. The damage investigation and prevention suggestion of Eucryptorrhynchus chinensis in Akesu, XinJiang. Agriculture Technology. 2007;27(1):61-2.

17. Qin K. Eucryptorrhynchus brandti harm to Ailanthus altissima var. Qiantouchun and its contro.. Entomology knowledge. 1996(5):278-9.

18. Yu Q, Chen C, Liu Z, Sun Y, Cao C, Bao S, et al. Occurrence and life-history of Eucryptorrhynchus chinensis in Lingwu, Ningxia. Chinese Journal of Applied Entomology. 2012;49(4):1005-9.

19. Bulletin of the State. Forestry Administration No. 4th of 2013.

20. Zhao Y, Chen Y. China Economic Insects Volume 20 (Coleoptera: Curculionidae) Beijing: Beijing Science Pres. 1980:149-50.

21. Borovec R. Catalogue of Palaearctic Coleptera. Leiden, Brill. 2013:231-2. 
22. Liu Z. Molecular Phylogeny and Species Differentiation of the Eucryptorrhynchus scrobiculatus and E.brandti.. Doctoral Thesis, Beijing Forestry University, Beijing, China. 2016.

23. Schluter D. The Ecology of Adaptive Radiation. Heredity. 2000;86(6):749-50. http://dx.doi.org/10.1111/j.1095-8312.1999.tb01165.x.

24. Zhang G, JI Y, Gao P, Wen J. Oviposition Behavior and Distribution of Eucryptorrhynchus scrobiculatus and E. brandti (Coleoptera: Curculionidae) on Ailanthus altissima (Mill.). Insects. 2019;10(9):284. http://dx.doi.org/10.3390/insects10090284.

25. Zhang G, Ji Y, Wen X, Li Q, Ren Y, Wen J. Oviposition behaviour of Eucryptorrhynchus brandti (Coleoptera: Curculionidae: Cryptorrhychinae) on Ailanthus altissima (Mill.) Swingle (Sapindales: Simaroubaceae). Biocontrol Sci Technol. 2017:1-15. http://dx.doi.org/10.1080/09583157.2017.1387233.

26. Davis SR. The Weevil Rostrum (Coleoptera: Curculionoidea): Internal Structure and Evolutionary Trends. Bulletin of the American Museum of Natural History. 2017;2017(416):1-76. http://dx.doi.org/10.1206/0003-0090-416.1.1.

27. Dennell R. The Structure and Function of the Mouth-Parts, Rostrum and Fore-Gut of the Weevil Calandra granaria L. Philos Trans R Soc Lond Ser B: Biol Sci. 1942;231(581):247-91. http://dx.doi.org/10.1098/rstb.1942.0003.

28. Kirby W, Spence W. An Introduction to Entomology: Comstock Pub. Co.; 1933.

29. Darwin C. The descent of man and selection in relation to sex, 2nd edn.. London: John Murray. 1875.

30. Menu F. Strategies of emergence in the chestnut weevilCurculio elephas(Coleoptera: Curculionidae). Oecologia. 1993;96(3):383-90.

31. Oberprieler RG, Marvaldi AE, Anderson RS. Weevils, weevils, weevils everywhere. Zootaxa. 2007;1668(1):491-520. http://dx.doi.org/10.11646/zootaxa.1668.1.24.

32. Chen F, Zhang C, Dai W. Fine Structure and Sensory Apparatus of the Mouthparts of the Maize Weevil,Sitophilus zeamais Motschulsky (Coleoptera: Curculionoidea: Dryophthoridae). Ann Entomol Soc Am. 2016;109(6):881-9. http://dx.doi.org/10.1093/aesa/saw054.

33. Bonal R, Espelta JM, Vogler AP. Complex selection on life-history traits and the maintenance of variation in exaggerated rostrum length in acorn weevils. Oecologia. 2011;167(4):1053-61. http://dx.doi.org/10.1007/s00442-011-2036-7.

34. Donaldson JS. Adaptation for oviposition into concealed cycad ovules in the cycad weevils Antliarhinus zamiae and A. signatus (Coleoptera: Curculionoidea). Biological Journal of The Linnean Society. 1992;47(1):23-35. http://dx.doi.org/10.1111/j.1095-8312.1992.tb00653.x.

35. Morimoto K, Hiroaki K. Morphological characters of the weevil head and phylogenetic implications (Coleoptera, Curculionoidea). Esakia. 2003;43:133-69.

36. Moon MJ, Park JG, Kim KH. Fine structure of the mouthparts in the ambrosia beetle platypus koryoensis (Coleoptera: Curculionidae: Platypodinae). Animal Cells Systems. 2008;12(2):101-8. http://dx.doi.org/10.1080/19768354.2008.9647162. 
37. Belhoucine L, Bouhraoua RT, Prats E, Pulade-Villar J. Fine structure and functional comments of mouthparts in Platypus cylindrus (Col., Curculionidae: Platypodinae). Micron. 2013;45:74-82. http://dx.doi.org/10.1016/j.micron.2012.10.017.

38. Moon M. Microstructure of mandibulate mouthparts in the greater rice weevil, Sitophilus zeamais (Coleoptera: Curculionidae). Entomol Res. 2015;45(1):9-15. http://dx.doi.org/10.1111/17485967.12086.

39. Davis SR. Delimiting baridine weevil evolution (Coleoptera: Curculionidae: Baridinae). Zoological Journal of the Linnean Society. 2011;161(1):88-156. http://dx.doi.org/10.1111/j.10963642.2010.00619.x.

40. Gao H. Characteristic, function, mechanics and bionic analysis of oriental mole cricket (Gryllotalpa orientalis Burmeister). Doctoral Thesis, Jilin University, Jilin, China. 2009.

41. Forsythe TG. Mouthparts and feeding of certain ground beetles (Coleoptera: Carabidae). Zoological Journal of the Linnean Society. 1983;79(4):319-76. http://dx.doi.org/10.1111/j.10963642.1983.tb01170.x.

\section{Figures}

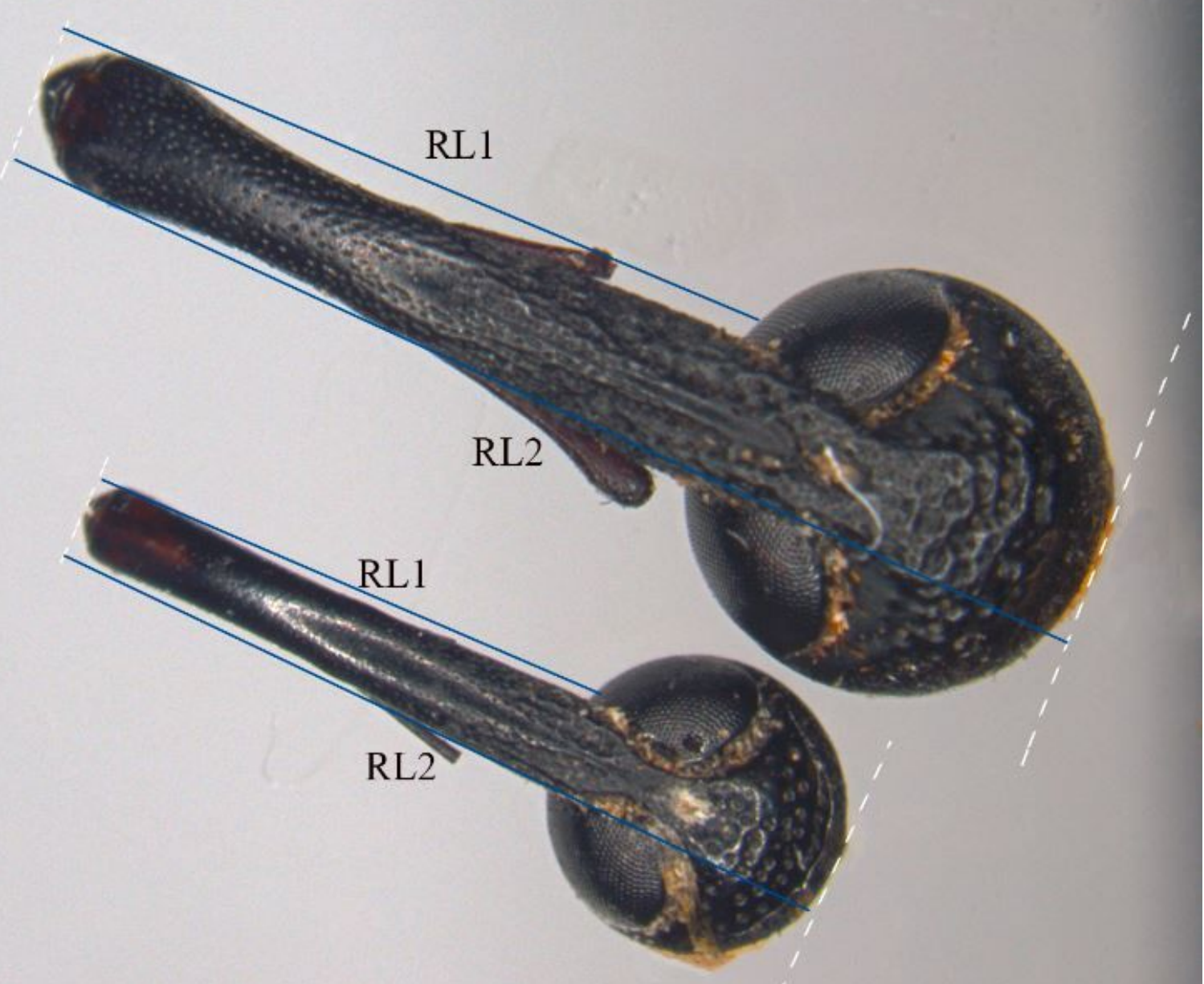


External morphology of rostra of Eucryptorrhynchus scrobiculatus female and E. brandti female. The larger of the two is the rostrum of E. scrobiculatus and the smaller is the rostrum of E.brandti
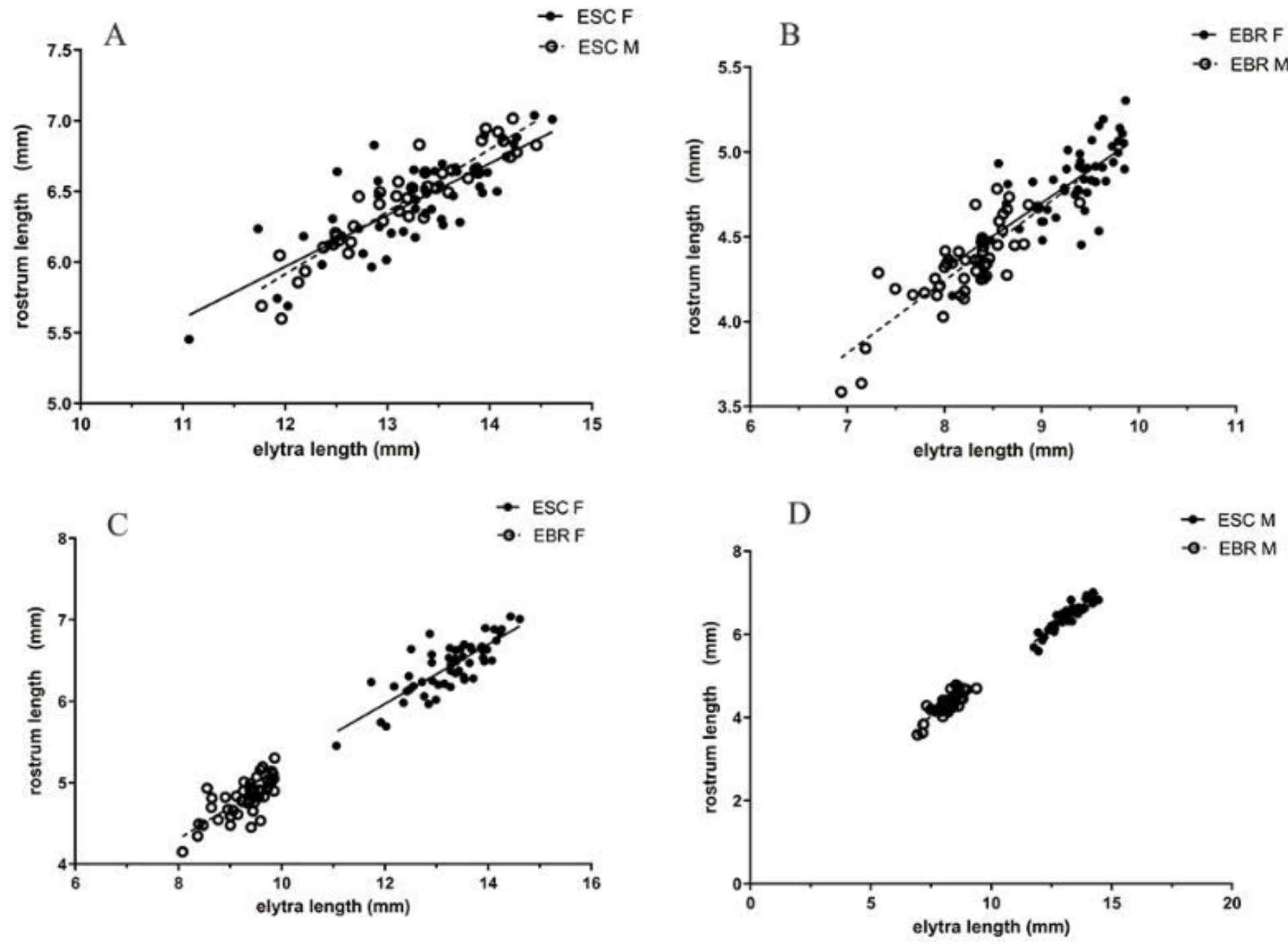

Figure 2

The allometric relationship between elytra length and rostrum length. A, Relationship between elytra length and rostrum length in E. scrobiculatus female and E. scrobiculatus male. B, Relationship between elytra length and rostrum length in E. brandti female and E. brandti male. C, Relationship between elytra length and rostrum length in E. scrobiculatus female and E. brandti female. D, Relationship between elytra length and rostrum length in E. scrobiculatus male and E. brandti male. 

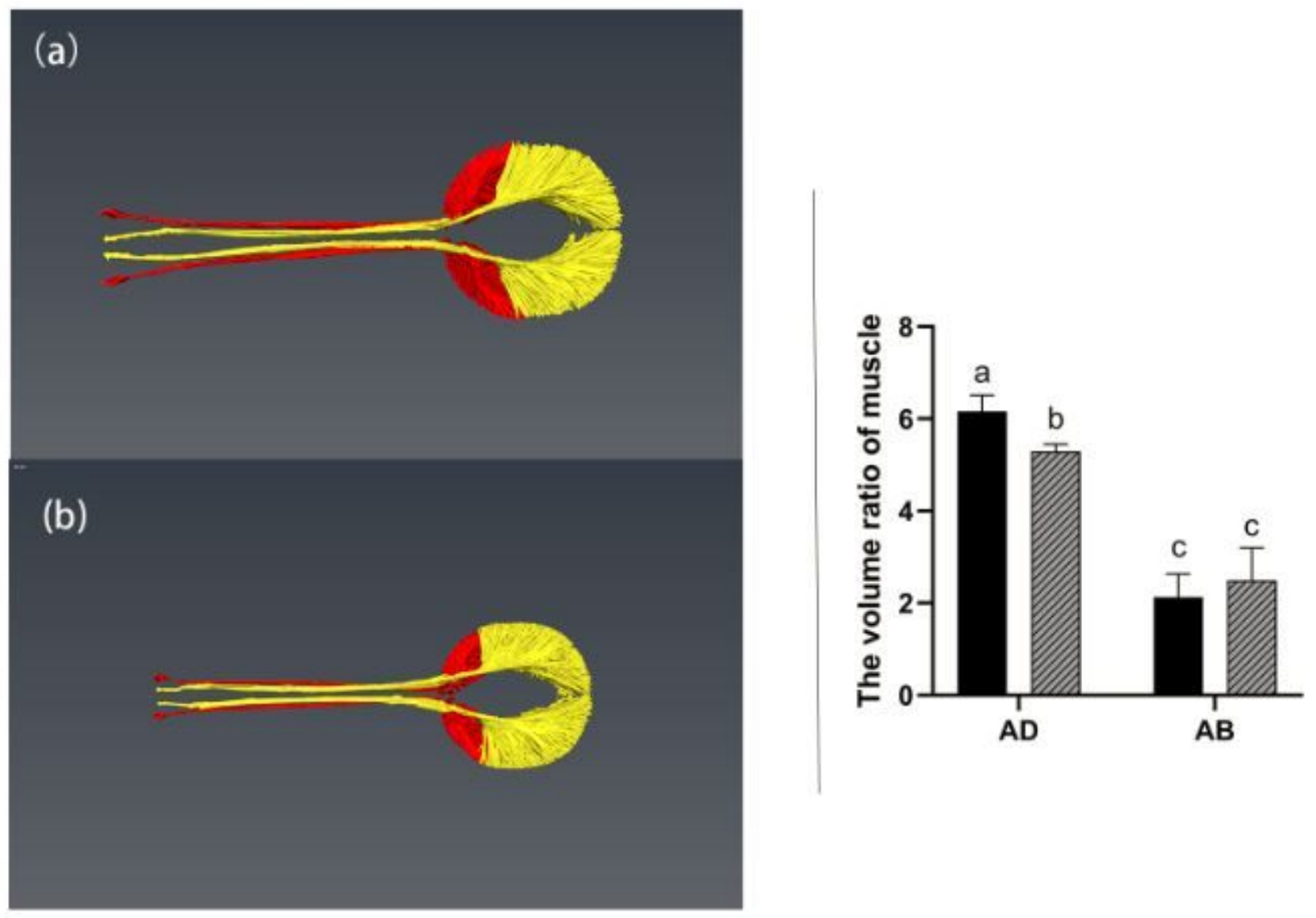

यSCF

- EBRF

\section{Figure 3}

Scanning electron micrographs showing rostra and mouthparts of E.scrobiculatus and E. brandti females. A, Anterior view of the stout E. scrobiculatus female rostrum, B, Anterior view of the thin E.brandti female rostrum. C, ventral view of E. scrobiculatus female mouthpart, which is situated at the apex of the rostrum. Mouthparts consist of a labrum (Lbr), a pair of mandibles (Md), a pair of maxillae $(\mathrm{Mx})$ and a labium (Lb). D, ventral view of E. brandti female mouthpart showing obvious differences to that of E. scrobiculatus female. E, apical view of E. scrobiculatus female mouthpart, F, apical view of E. brandti female mouthpart. $\mathrm{G}$, the left mandible of E. scrobiculatus, $\mathrm{H}$, the right mandible of $\mathrm{E}$. brandti. Ant, antenna; C.e, compound eye; Mout, mouthparts; Ros, rostrum; Fn, front; Hd, head. 


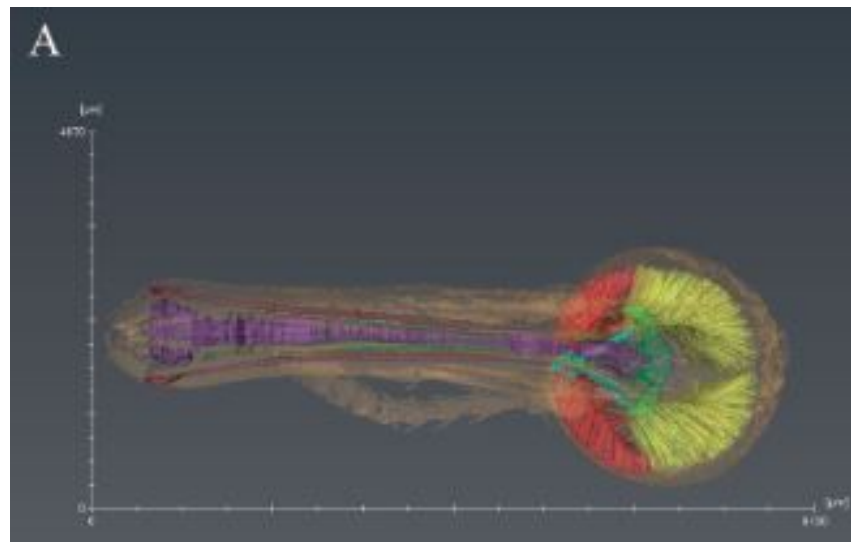

$\mathrm{C}$

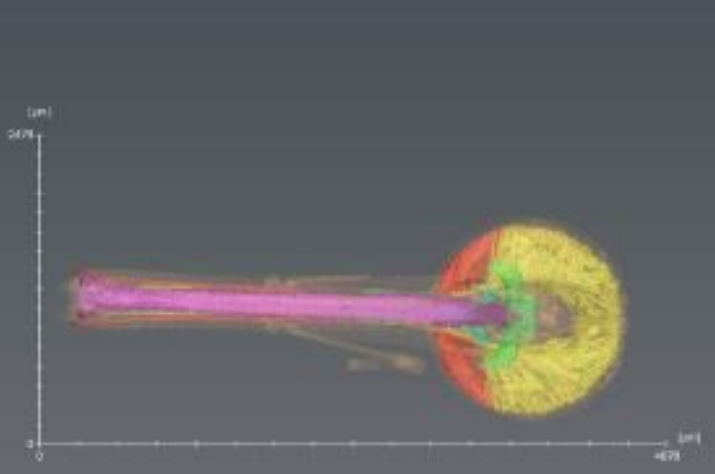

D
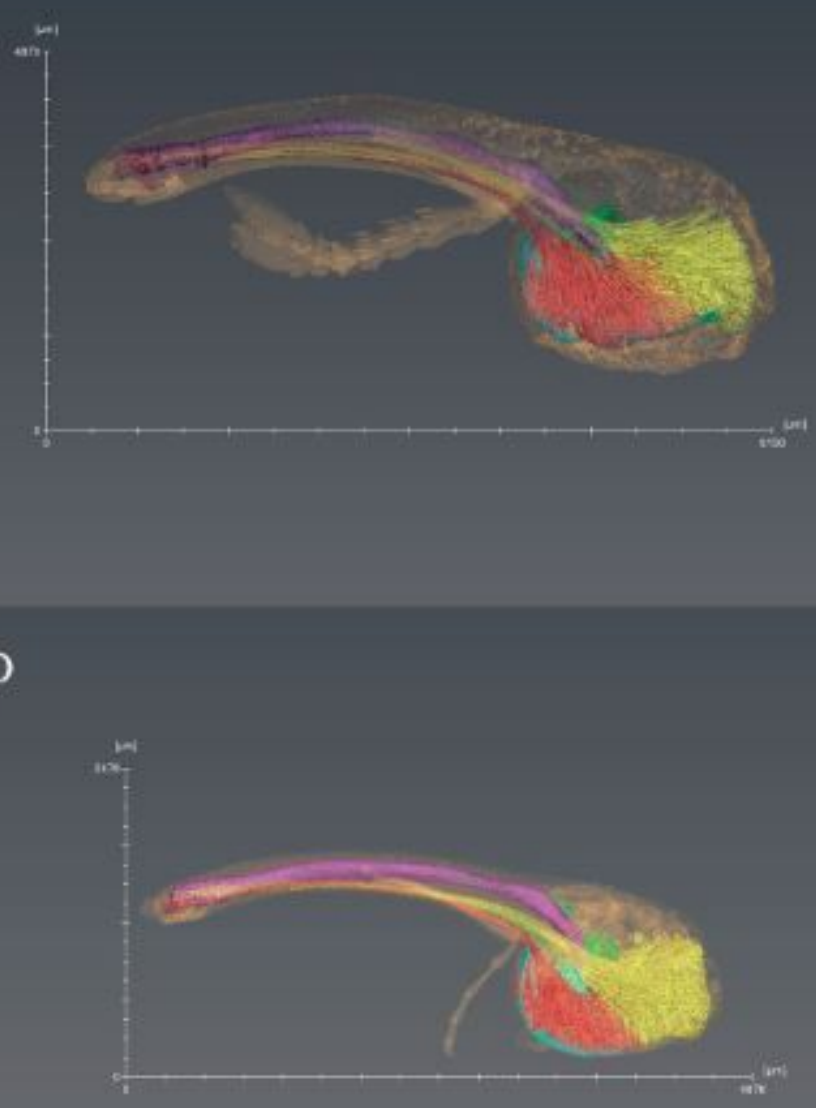

pharynx; cerebrum (nervous tissue);

part of tentorium;

mandibular abductor tendons+ muscles;

mandibular adductor tendons+ muscles;

\section{Figure 4}

$\mu C T$ scan of E.scrobiculatus and E. brandti females, adult head, cuticle of head rendered semitransparent to reveal internal anatomy. A, Anterior view of E. scrobiculatus female; B, Left side view of E. scrobiculatus female; C, Anterior view of E. brandti female; D, Left side view of E. brandti female. 

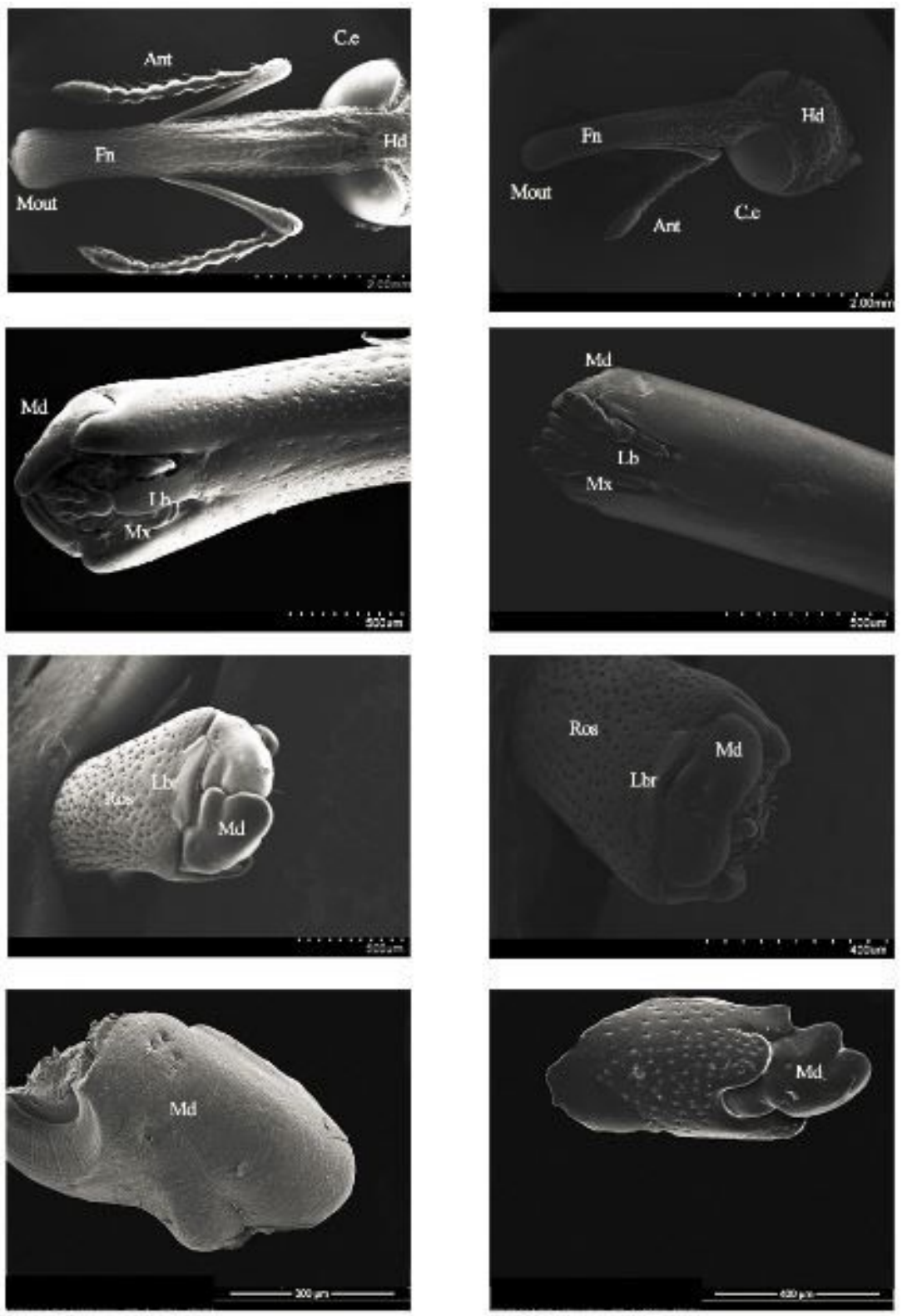

\section{Figure 5}

Mandibular muscles of E. scrobiculatus females and E. brandti females. The picture on the left is a threedimensional reconstruction of the mandibular muscles of two kinds of weevils. (a) Mandibular muscles of E. scrobiculatus females, the red part represents the abductor muscles, the yellow part represents the adductor muscles; (b) Mandibular muscles of E. brandti females, the red part represents the abductor muscles, the yellow part represents the adductor muscles. The picture on the right is the volume ratio of mandibular muscles of E. scrobiculatus females (ESC F)and E. brandti females (EBR F), AD is the adductor muscle, $A B$ is the abductor muscle, (mean $\pm S E$, different letters "a" "b" "c" indicate statistically significant differences).

\section{Supplementary Files}

This is a list of supplementary files associated with this preprint. Click to download. 
- Supplementarymaterials.docx

Page 21/21 